Rodrigo Marques, Aline Oliveira Vieira, Os sentidos Atribuídos pelos Jovens à Educação em Valores... Felipe Rodrigues Costa, Otávio Guimarães Tavares e

Wagner Santos

\title{
OS SENTIDOS ATRIBUÍDOS PELOS JOVENS À EDUCAÇÃO EM VALORES NO CONTEXTO DE UM PROJETO SOCIAL ${ }^{1}$
}

Recebido em: 15/03/2016

Aceito em: 12/10/2016

Rodrigo Marques
Aline Oliveira Vieira
Universidade Federal do Espírito Santo (UFES)
Vitória - ES - Brasil
Felipe Rodrigues Costa
Universidade de Brasília (UNB)
Brasilia - DF - Brasil
Otávio Guimarães Tavares
Wagner Santos
Universidade Federal do Espírito Santo (UFES)
Vitória - ES - Brasil

RESUMO: O estudo analisa os sentidos que os jovens produzem no aprendizado com a educação em valores de um projeto social do município de Serra, estado do Espírito Santo. Utiliza como referencial teórico-metodológico o estudo de caso etnográfico e faz uso dos seguintes instrumentos: observação não participante, registro no diário de campo, grupo focal e entrevista semiestruturada. Os sujeitos da pesquisa foram 40 jovens com idade entre 12 e 15 anos. A apropriação e os sentidos que são atribuídos aos valores partem de interesses individuais mostrando que apesar de frequentarem um lugar comum os jovens produzem diferentes sentidos mesmo quando sua participação no projeto está atrelada a obrigações impostas pela família ou pelas exigências do projeto para que seja possível sua inserção nas atividades.

PALAVRAS CHAVE: Atividades de Lazer. Educação Física e Treinamento. Adolescente.

\section{THE SENSES OF THE YOUNG PEOPLE TO EDUCATION IN VALUES IN THE CONTEXT OF A SOCIAL PROJECT}

ABSTRACT: The study analyzes the way that young people produce learning with education in values of a social project of the city of Serra, State of Espirito Santo. Used as theoretical and methodological framework ethnographic case study and makes use of the following instruments: non-participant observation, journaling of field, focus group and semi-structured interview. The study subjects were 40 young people aged between

\footnotetext{
${ }^{1}$ Pesquisa financiada pela Fundação de Amparo à Pesquisa do Espírito Santo / Fapes.
} 
Rodrigo Marques, Aline Oliveira Vieira, Os sentidos Atribuídos pelos Jovens à Educação em Valores... Felipe Rodrigues Costa, Otávio Guimarães Tavares e

Wagner Santos

12 and 15 years. The appropriation and meanings that are assigned to the values start from individual interests showing that despite attending commonplace young people produce different directions even when their participation in the project is linked to the obligations imposed by the family or by the project requirements so that you can your inclusion in the activities.

KEYWORDS: Leisure Activities. Physical Education and Training. Adolescent.

\section{Introdução ${ }^{2}$}

Estudos que analisaram a produção do conhecimento sobre juventude nas áreas de educação, ciências sociais e serviço social sinalizaram que as pesquisas, até o início dos anos 2000, selecionaram elementos empíricos capazes de enunciar algo sobre a condição juvenil no Brasil. Todavia, apresentaram dificuldade em delimitação conceitual da noção de juventude (SPOSITO, 2009).

Há um consenso que aponta a necessidade de os estudos compreenderem juventude para além de uma ideia de etapa do momento da vida, mas como categoria estruturante de vida social. Nesse sentido, a primeira década dos anos 2000 apresentou diferentes pesquisas que discutem a juventude a partir do ponto vista relacional, com a preocupação de dar visibilidades aos modos de produção de experiências juvenis, tratando de compreender o que o jovem faz com o que fazem com ele (SPOSITO, 2009).

Segundo Freitas (2013), é importante perceber que a juventude não é uma unidade social, assim tanto suas diversidades quanto suas particularidades, necessariamente, devem ser tomadas em consideração pelo intérprete que busca compreendê-las e explicá-las. Faz-se necessária, então, a compreensão sobre as juventudes, reconhecendo esses indivíduos como homens plurais, situados como protagonistas.

\footnotetext{
${ }^{2}$ Pesquisa aprovada no Comitê de Ética em pesquisa da Ufes, sob o no 1549913.4 .0000 .5542
} 
Rodrigo Marques, Aline Oliveira Vieira, Os sentidos Atribuídos pelos Jovens à Educação em Valores... Felipe Rodrigues Costa, Otávio Guimarães Tavares e

Wagner Santos

Contudo, Dayrel e Carrano (2014) demonstram que existe uma fragilidade em reconhecer essas juventudes como sujeitos capazes de se apropriar e emitir sentidos sobre os valores com autonomia e protagonismo, principalmente quando se discute a juventude pobre, que deveria ter seus direitos garantidos. Porém, para Charlot (2001), ela é entendida como ameaça ao bem-estar social, tornando-se objeto de investimentos de políticas públicas e palco de profundas ambiguidades que revelam o verdadeiro olhar social direcionada a elas.

Nesse caso, os projetos sociais ${ }^{3}$ configuram-se como uma alternativa de investimento por parte das políticas públicas para o atendimento às juventudes, ${ }^{4}$ oferecendo-lhes atividades esportivas, profissionalizantes e/ou complementares à escolarização formal, visando à promoção da integração social e à promoção da saúde.

Ao realizarmos uma análise da produção acadêmica sobre projetos sociais nas cinco principais revistas da educação física, os estudos de Lira e Dimenstain (2004) e Molina, Silva e Silveira (2004) nos indicaram que, nas diretrizes dos projetos sociais por eles estudados, não pode estar de fora a mediação dos valores como uma importante ferramenta para alcançarem os objetivos atitudinais criados para o atendimento aos jovens.

A educação física evidencia a discussão sobre os valores e seus significados nos projetos sociais, além, de suas contribuições na formação dos jovens pela descrição em ordem de importância dos valores eleitos por eles, visando compreender os modos de

\footnotetext{
${ }^{3}$ Os projetos sociais que são empreendimentos planejados e que consistem em um conjunto de atividades inter-relacionadas e coordenadas para alcançar objetivos específicos dentro dos limites de um orçamento e de um período de tempo Organização das nações Unidas (ONU). Seu objetivo é transformar uma parcela da realidade, diminuindo ou eliminando um déficit, ou solucionando um problema social (BELO HORIZONTE, 2007, p. 87).

${ }^{4}$ Definimos juventudes para muito além de um bloco único, no qual a idade é o fator predominante. Por essa linha, vem se tornando cada vez mais corriqueiro o emprego do termo juventudes, no plural, no sentido não de dar conta de todas as especificidades, mas, justamente, apontar a enorme gama de possibilidades presente nessa categoria (ABRAMOVAY; ANDRADE; ESTEVES, 2007, p. 22)
} 
Rodrigo Marques, Aline Oliveira Vieira, Os sentidos Atribuídos pelos Jovens à Educação em Valores... Felipe Rodrigues Costa, Otávio Guimarães Tavares e

Wagner Santos

intervir mediados pelos valores (SALDANHA, 2012; SAWITZKI et al., 2013; MAZO, 2011; MELLO et al., 2009).

Porém, as pesquisas na educação física com projetos sociais têm produzido poucas iniciativas que dialoguem com os jovens que praticam esse lugar. ${ }^{5}$ Mello et al. (2009) evidenciaram a necessidade de "dar voz" aos participantes, em nosso caso, "dar voz" para que exponham os sentidos que lhes atribuem e como se apropriam desses valores, visando à sua formação como sujeitos de desejos e anseios.

Esta pesquisa procura, no diálogo com jovens de 12 a 15 anos de idade, participantes de um projeto social, problematizar as seguintes questões: quais são as propostas de intervenções de valores dentro dos projetos sociais aos quais as juventudes estão submetidas? Quais valores priorizam? Diante dessas questões, procuramos analisar os sentidos que os jovens produzem sobre os valores, ao se apropriarem ${ }^{6}$ das práticas corporais ministradas nas oficinas de um projeto social de Serra/ES.

Compreendemos os sentidos fundamentados em Charlot (2000) como um enunciado ou um acontecimento que possam ser postos em relação com outros em um sistema, ou em um conjunto. Quando digo "Isso realmente tem um sentido para mim", a pessoa está indicando que dá importância ao fato, que para ela tem um valor, ou “[ [... se isso não tiver sentido, é porque, como dizem os colegiais, "não vale nada"" (CHARLOT, 2000, p. 57).

\footnotetext{
${ }^{5}$ Entendemos que o lugar é a ordem (seja qual for), segundo a qual distribuem elementos nas relações de coexistência. Aí se achando, portanto, excluída a possibilidade de duas coisas ocuparem o mesmo lugar. Impera a lei do "próprio": os elementos considerados se acham uns ao lado dos outros, cada um situado num lugar "próprio" e distinto que o define (CERTEAU, 2012).

${ }^{6}$ Apropriação, para Certeau (2012), é uma operação de produção que, embora não fabrique nenhum objeto, assinala a sua presença a partir das maneiras de utilizar os produtos que lhes são impostos. As práticas de apropriação (táticas) são o contraponto às operações (estratégias) que visam a disciplinar e regular o consumo cultural.
} 
Rodrigo Marques, Aline Oliveira Vieira, Os sentidos Atribuídos pelos Jovens à Educação em Valores... Felipe Rodrigues Costa, Otávio Guimarães Tavares e

Wagner Santos

A base teórica deste trabalho está situada em autores que discutem valores (MENIN, 2002; WERNECK, 2010; LEMOS, 2006; PONCE，2009; LUCAS; PEREIRA; MONTEIRO, 2012), experiência e narrativa (BENJAMIN, 1987), produção de sentidos e relação com o saber (CHARLOT, 2000) e também relações de apropriação, consumo produtivo, espaços e lugares (CERTEAU, 2012).

\section{Referencial Teórico-Metodológico}

A pesquisa se propôs analisar os sentidos atribuídos pelos jovens à educação em valores, no entendimento de sentidos como uma referência à história dos sujeitos, às suas expectativas, às suas referências, à sua concepção da vida, às suas relações com os outros, à imagem que têm de si e a que quer dar de si aos outros (CHARLOT, 2000). Assim, procuramos identificar a produção dos sentidos por uma leitura dos modos de apropriação, usos, consumos produtivos ${ }^{7}$ (CERTEAU, 2012) que os jovens constituem com o ministrado no "lugar" Projeto Social.

No diálogo com Certeau (2012), compreendemos o projeto social, localizado no município de Serra/ES, fundado em 2005, mantido e coordenado pela Ordem Religiosa Escolas Pias - Padres Escolápios que oferecem aos jovens da região atendimento socioeducativo no contraturno escolar, sendo eles beneficiados com a assistência de voluntários e profissionais de diversas áreas, como um lugar onde a ordem distribui "[...] elementos nas relações de coexistência implicando uma indicação de estabilidade" (CERTEAU, 2012, p. 212).

\footnotetext{
${ }^{7}$ Entende-se por consumidor produtivo aquele que metaforiza a ordem dominante, fazendo-a funcionar em outro registro, modificando-a, sem deixá-la. Procedimentos de consumo que conservam a sua diferença no próprio espaço organizado pelo ocupante (CERTEAU, 2012).
} 
Rodrigo Marques, Aline Oliveira Vieira, Os sentidos Atribuídos pelos Jovens à Educação em Valores... Felipe Rodrigues Costa, Otávio Guimarães Tavares e

Wagner Santos

Para analisarmos a produção de sentidos com a educação em valores ofertada no lugar projeto social, dispomo-nos a identificar essa produção no modo como os jovens praticam esse lugar e, assim, constituem espaços. Para Certeau (2012), os espaços são formados pelas práticas que os sujeitos realizam no lugar - em seus usos e modos de apropriação com o que ali é ofertado, subvertendo a ordem imposta - modificando-o e, assim, tornando-o um lugar praticado.

O autor sinaliza que, para compreender a constituição dos espaços, faz-se necessário nos colocarmos em um exercício de escuta e observação da narrativização das práticas no cotidiano investigado. Para isso, dispomo-nos a analisar a produção de sentidos dos jovens com a educação em valores, ouvindo suas narrativas de experiência nas oficinas do projeto social. De acordo com Benjamim (1987), a prática do narrar é uma forma de os sujeitos contarem história, e, se as histórias também são a vida que acontece num tempo e num contexto, podem ser contadas e recontadas de diferentes maneiras. Benjamin (1987) sinaliza que narrar é uma arte cada dia mais rara, não só porque poucos sabem fazê-lo, mas também porque se sustenta num difícil terreno: a experiência, que se passa de pessoa a pessoa.

Interessa-nos entender, pelas narrativas dos jovens participantes do projeto, como as experiências com educação em valores passadas/ensinadas tocaram os jovens e, ao tocá-los, como estes produziram sentidos ao ofertado.

$\mathrm{O}$ aprendizado da e pela experiência interpelaria o habitualmente pensado e os significados instalados pela linguagem corrente, perturbando o discurso de verdade e o sujeito idêntico a si mesmo no qual essa arte-técnica se assenta, fazendo os seus sujeitos pensarem, se distendendo e problematizando a sua pretensão de abarcamento da realidade e de totalidade (PAGNI, 2010, p. 25). 
Rodrigo Marques, Aline Oliveira Vieira, Os sentidos Atribuídos pelos Jovens à Educação em Valores... Felipe Rodrigues Costa, Otávio Guimarães Tavares e

Wagner Santos

Esta pesquisa é de caráter qualitativo do tipo etnográfico. ${ }^{8}$ Os sujeitos foram 40 jovens participantes de um projeto social, localizado no município de Serra/ES, cuja proposta pedagógica $^{9}$ é baseada nos valores humanos, tendo as práticas corporais como uma das ferramentas para sua viabilização. A escolha do projeto baseia-se nos fatos: no atendimento à juventude, são ofertadas oficinas voltadas diretamente para a educação em valores humanos; há profissionais formados em educação física e educadores sociais trabalhando com diferentes práticas corporais.

A permanência deste pesquisador no presente projeto ocorreu entre os meses de agosto e novembro de 2014. Durante esse período, acompanhamos as práticas desses jovens no processo de intervenção em valores nas oficinas de Educação Física, Educação em Valores Humanos, Xadrez, Capoeira e Break Dance.

A participação dos jovens nas oficinas oferecidas pelo projeto social ocorre da seguinte forma: todos são obrigados a participar da Oficina de Valores Humanos e podem escolher outra de seu interesse. A troca da modalidade escolhida se dá após um período de seis meses.

O projeto social atende a jovens com idade entre 6 e 15 anos, porém o motivo que nos levou a tomar a decisão de só pesquisar a faixa etária de 12 a 15 está baseado na compreensão dos estágios de desenvolvimento do conhecimento propostos por Piaget (2003). Para o autor, os jovens com a idade de 12 a 15 anos encontram-se em um estágio conhecido como o período operatório formal, em que o pensamento já está formado para abstrações e o sujeito tem capacidade de desenvolver conhecimentos.

\footnotetext{
${ }^{8}$ Trata-se “[...] da realização pluriparadigmática de investigações organizacionais (da escola ou não) que encontram nos estudos concretos dos contextos singulares de acção as condições de formulação de perspectivas, teorias e conclusões de implicação teórico-prática de múltiplos valores e sentido. A opção pelo estudo de caso numa estratégia investigativa não significa, portanto, a escolha de um paradigma de investigação; no entanto, a adoção de um paradigma investigativo pode propor o estudo de caso" (SARMENTO, 2003, p. 140).

${ }^{9}$ Informação obtida no Projeto Político-Pedagógico do Projeto Social.
} 
Rodrigo Marques, Aline Oliveira Vieira, Os sentidos Atribuídos pelos Jovens à Educação em Valores... Felipe Rodrigues Costa, Otávio Guimarães Tavares e

Wagner Santos

Para Rappaport (1981, p. 75) no período das operações formais:

[...] o sujeito será então capaz de formar esquemas conceituais abstratos (conceituar termos como o amor, fantasia, justiça, esquema, democracia) e realizar com eles operações mentais que seguem os princípios da lógica formal, o que lhe dará, sem dúvida, uma riqueza em termos de conteúdo e de flexibilidade de pensamento. Com isso adquire capacidade para criticar os sistemas sociais e propor novos códigos de conduta; discute os valores morais de seus pais e constrói os seus próprios (adquirindo, portanto, autonomia); torna-se capaz de aceitar suposições pelo gosto da discussão; faz sucessão de hipóteses que expressa em proposições para depois testá-las; procura propriedades gerais que permitam dar definições exaustivas, declarar leis gerais e ver significação comum em material verbal; os seus conceitos espaciais podem ir além do tangível finito e conhecido para conceber o infinitamente grande ou o infinitamente pequeno; torna-se consciente de seu próprio pensamento, refletindo sobre ele a fim de oferecer justificações lógicas para os julgamentos que faz; lida com relações entre relações, etc.

Sendo assim, entendemos que, nessa faixa etária, esses jovens poderão expressar os sentidos que eles atribuem aos valores, a partir de conhecimentos preexistentes, mas que já foram assimilados e ressinigficados, expressando-os com autonomia.

Dos 40 jovens estudados, 22 frequentam o espaço no turno matutino e 18 no vespertino. Todas as oficinas acontecem no contraturno escolar, visto que a matrícula no sistema regular de ensino é condição para participar do projeto.

Como instrumentos para coleta de dados, utilizamos as anotações no diário de campo e a observação não participante, porém reconhecemos, de acordo com Sarmento (2003), que não existe um modo de realizar a observação dos contextos de ação que não seja num certo sentido sempre participante.

Durante o período de observação dos jovens, registramos as falas espontâneas advindas das relações que se formalizam em suas narrativas. A observação no acompanhamento das oficinas com o registro do diário de campo possibilitou-nos captar os sentidos apresentados nas falas espontâneas, nas expressões, nas relações 
Rodrigo Marques, Aline Oliveira Vieira, Os sentidos Atribuídos pelos Jovens à Educação em Valores... Felipe Rodrigues Costa, Otávio Guimarães Tavares e

Wagner Santos

conflituosas ou não durante os momentos em que estivemos presente no contexto pesquisado.

Outras ferramentas utilizadas foram o grupo focal e a entrevista semiestruturada. Dividimos os jovens em três grupos para realizar o grupo focal. Para Dias (2000), o ponto central desta ferramenta é identificar percepções, sentimentos, atitudes e ideias dos participantes a respeito de um determinado assunto, em que seus objetivos variam de acordo com a abordagem ao objeto da pesquisa.

Todos os 40 jovens participariam do grupo focal, contudo não foi possível realizar essa atividade com nove jovens do turno vespertino, porque eles deixaram de participar momentaneamente das oficinas do projeto para frequentar um curso de fotografia gratuito que estava acontecendo no bairro, voltado para a formação para o mercado de trabalho, e outros três que não compareceram no dia do grupo focal. Assim, tivemos um total de 28 jovens participantes; no primeiro grupo, nove jovens frequentaram as oficinas no turno matutino; outro também com nove jovens do vespertino; e o terceiro foi composto por dez alunos do matutino.

Após o término do grupo focal, analisamos as filmagens e criamos um roteiro baseado nas falas dos jovens para as entrevistas semiestruturadas. Elas foram individualizadas e realizadas com seis jovens, dois representantes de cada um dos três grupos focais. A forma de escolha desses seis participantes se deu com a análise da transcrição de todo o conteúdo do grupo focal, que revelou algumas pistas sobre suas apropriações do conteúdo de valores. As entrevistas individualizadas contaram com seis questões orientadoras.

As entrevistas com esses três grupos de jovens tiveram seis questões orientadoras e, de acordo com a necessidade, novas questões iam sendo introduzidas 
Rodrigo Marques, Aline Oliveira Vieira, Os sentidos Atribuídos pelos Jovens à Educação em Valores... Felipe Rodrigues Costa, Otávio Guimarães Tavares e

Wagner Santos

para dar conta de atender às novas demandas de informações que eram rememoradas por eles. Todos tiveram liberdade para se expressar de acordo com o seu desejo e foi respeitado o direito daqueles que não se manifestaram, mesmo com o estímulo do entrevistador para que eles expusessem suas opiniões. Apenas um jovem do primeiro grupo preservou seu direito de não manifestar sua opinião.

\section{Evidências Narradas}

Ao lermos na íntegra todas as fontes produzidas, identificamos três grandes conjuntos de análises que nortearam o estudo: a) as relações entre o projeto social, o contexto social e a família; b) os sentidos da função do "EU" estar em um projeto social; c) os sentidos com as práticas corporais: o fazer com as oficinas.

O primeiro conjunto de análise justifica-se por apresentar as diferentes macroestruturas sociais: projeto social, contexto social e família que podem influenciar diretamente os modos de apropriação e produção de sentidos que os jovens atribuem às diferentes relações existentes nesses lugares, nos quais esses autores assumem variados códigos para serem aceitos pelos grupos que ali impõem suas marcas. O segundo fornece pistas para entendermos os diferentes interesses que levam os jovens a frequentar o lugar e os consumos produtivos apropriados das práticas ali desenvolvidas. Já o terceiro conjunto apresenta as diferentes práticas corporais desenvolvidas no projeto e evidencia a produção de sentidos e apropriações que os jovens adquirem desses fazeres com as oficinas.

\section{Os Lugares: O Projeto, o Contexto Social e a Família}

Os projetos sociais são como um exercício de cidadania, pois devolvem as pessoas as suas vivências cotidianas e levam a uma transposição de barreiras sobre 
Rodrigo Marques, Aline Oliveira Vieira, Os sentidos Atribuídos pelos Jovens à Educação em Valores... Felipe Rodrigues Costa, Otávio Guimarães Tavares e

Wagner Santos

preconceitos presentes na sociedade em benefício do outro, colaborando para a conscientização do indivíduo e do papel que ele desempenha na sociedade (GARANHANI; TASSA, 2013).

Contudo, além do projeto social, outros lugares influenciam os valores que dão sentido e direção aos caminhos trilhados pelos jovens, tornando múltiplas as suas referências e relações estabelecidas com os diversos saberes nos diferentes lugares, como sinalizado nas narrativas:

Respeito, educação. A gente aprende muitas coisas na rua. As pessoas falam, conversam com a gente na escola, em casa. O que a gente aprende fora daqui é a mesma coisa, ainda mais na escola (REGIANI, grupo Focal, 2014).

Faz melhorar meus atos, porque, em vez de eu ser uma pessoa agressiva, eu sou uma pessoa mais calma e diferente do que eu aprendo na rua. Aqui faz a diferença. A rua é outra linguagem. Aqui dentro é uma linguagem e na rua é outra... Qual é? (RÔMULO, grupo Focal, 2014).

Segundo Charlot (2000), os aprendizados acontecem na relação com o mundo em um sentido geral, mas também com os mundos particulares, meios, espaços e lugares nos quais se vive e aprende os diferentes estatutos, a partir das relações que mantêm. Enfim, o aprendizado não é apenas marcado pelo local, mas pelo convívio entre as pessoas.

O contexto social em que o projeto social está inserido é marcado pela violência, ${ }^{10}$ exclusão social e tráfico de drogas, contudo se faz necessário investigarmos não só as leituras negativas e macrossociais, mas também como os praticantes do cotidiano produzem práticas de resistência nas maneiras de fazer (CERTEAU, 2012).

\footnotetext{
${ }^{10}$ Segundo o Instituto Brasileiro de Geografia e Estatística (IBGE), no ano de 2013, um total de 3.794 homicídios de adolescentes de 16 e 17 anos, foram notificados. Na faixa de 16 e 17 anos, destacam-se Alagoas, Espírito Santo e Ceará pelas elevadas taxas no ano de 2013. (Disponível em: < http://www.mapadaviolencia.org.br/pdf2015/mapa2015_SumarioExecutivo.pdf.>. Acesso em: 15 nov. 2014).
} 
Rodrigo Marques, Aline Oliveira Vieira, Os sentidos Atribuídos pelos Jovens à Educação em Valores... Felipe Rodrigues Costa, Otávio Guimarães Tavares e

Wagner Santos

O fato de essa juventude estar exposta implica preocupações que assolam as comunidades no entorno do projeto: a criminalidade, o alcoolismo, o tráfico de drogas e as brigas de gangues, tornando o cotidiano dos jovens uma rotina de adaptações para transformar os diferentes lugares, espaços praticáveis, conforme evidenciado nas narrativas:

Porque no tráfico é pouca gente que trata os outros com educação. Eu aprendi esse modo de falar: 'Qual é doido'! E aí! (RÔMULO, grupo Focal, 2014).

Parece ser normal as crianças falarem de roubo, morte, brigas e discussões. Elas são muito impacientes e intolerantes (Anotação no diário de campo, 2014).

Sobre um vídeo em que as pessoas entregavam o que as pessoas haviam perdido, um jovem disse: 'Ser honesto é ser burro'! (Anotação no diário de campo, 2014).

Uma notícia apresentada pelo professor de que um adolescente fora retirado de casa por bandidos que o executaram e o jogaram em um valão do bairro, um aluno respondeu: 'Isso é normal a falta de estrutura na família causa isso, se as nossas famílias nos dessem apoio isso poderia melhorar para todos' (Anotação no diário de campo, 2014).

Esses cotidianos se apresentam como lugares e espaços habitados onde se materializam, de formas complexas, os consumos produtivos, em que os praticantes se articulam formando as redes de relações que aparecem e desaparecem de acordo com as normas que representam os diferentes lugares (CERTEAU, 2012).

Pais (1993) fomenta para uma análise dessa juventude um olhar multi e interdisciplinar, de maneira a aprender os modos de agir dos jovens nos lugares onde eles tecem as culturas juvenis, exercício social em que esses atores combinam continuidades e descontinuidades. Assim, interessou-nos dar visibilidade na pesquisa ao modo como os jovens produzem sentidos em estar em um projeto social, com seus aspectos relacionais, com Eu-Outro, sendo o Outro a família, a escola, o projeto social, os amigos etc. 
Rodrigo Marques, Aline Oliveira Vieira, Os sentidos Atribuídos pelos Jovens à Educação em Valores... Felipe Rodrigues Costa, Otávio Guimarães Tavares e

Wagner Santos

Percebemos que os valores da educação, da honestidade e da família são citados pelos jovens, porém, em suas narrativas, aparenta ser "normal” jovens sendo mortos, esclarecendo que praticar a honestidade é um ato de "burro". Esses são fatos que parecem ter se tornado parte dessa cultura juvenil. A apropriação de suas experiências é influenciada e enraizada na sua formação. Como observamos, os relatos apresentados revelam uma infeliz rotina com a qual todos demonstram estar acostumados.

Contudo, de acordo com Charlot (2000), não basta dar a situação por resolvida, justificando o desinteresse dos jovens por causa da classe social ou da família ou pensar de maneira determinista, lançando uma leitura negativa sobre a realidade. Em vez disso, é preciso fazer uma leitura positiva dos jovens, levando em conta sua história de vida, seus desejos e suas atividades cotidianas. Conforme Pais (1993), que adota a perspectiva metodológica do curso de vida para compreender as formas de transição dos jovens para a vida adulta, devemos desvelar suas produções culturais, permitindo um exame mais abrangente sobre o tempo pessoal, histórico, as trajetórias individuais e as estruturas sociais.

Para Lemos (2006), os jovens constroem sua identidade por meio das relações que estabelecem com o mundo e com os outros, a partir do grupo social ao qual pertencem, do contexto familiar, das experiências individuais e de acordo com os valores, ideais e normas que organizam sua visão de mundo.

Esses diferentes lugares, segundo Charlot (2000), influenciam os modos como esses jovens vão apropriar-se do mundo, partilhando seus valores, entrando em um conjunto de relações e processos que constituem um sistema de produção de sentidos em que eles dizem quem são, qual é o seu lugar e quem são os outros. 
Rodrigo Marques, Aline Oliveira Vieira, Os sentidos Atribuídos pelos Jovens à Educação em Valores... Felipe Rodrigues Costa, Otávio Guimarães Tavares e

Wagner Santos

A família, como primeira célula social, não suprindo as necessidades formativas, abre oportunidades para outros lugares mediarem os saberes a serem apropriados pelos jovens. Assim, os diferentes contextos influenciam a sua maneira de produzir sentidos e o consumo produtivo dos diferentes valores, conforme apresentado na narrativa abaixo:

Se eu estivesse em casa, estaria escutando minha mãe discutir com minha avó. Eu parei de discutir com minha mãe, estou parando de xingar e conseguindo me controlar, porque aqui, se falarmos palavrões, nós temos que ficar escutando e, se eu arranjar briga vou perder amigo e posso ser expulsa e dar algum tipo de 'BO' (problema) (ROSANA, grupo Focal, 2014).

Segundo Benjamin (1987), as experiências negativas advindas das realidades sociais são formas de corromper uma geração, tornando-a abandonada, sem teto, numa paisagem diferente de tudo e em um campo de forças, de correntes e explorações destruidoras, no qual se situa o frágil ser humano.

Assim, caberia à família ser um lugar supostamente autorizado para estimular a apropriação de práticas valorativos por partes dos jovens. Contudo, para Pradel e Daú (2009), a preocupação com a educação para valores parece estar indicada exclusivamente na ação da escola, sem uma efetiva parceria com e por parte das famílias.

O projeto, diferente das práticas da família e das ruas, representa outras possibilidades de aprendizado que estimulam o interesse dos jovens de frequentar e participar daquele contexto, conforme suas regras. Os jovens com quem realizamos a pesquisa atribuem às ações desenvolvidas no projeto uma mudança de comportamento naquele contexto como: discutir menos com os colegas, evitar os palavrões, respeitar o outro e ser tolerante, já em sua relação com a família vimos que os jovens discutem menos com os pais, além de atender prontamente os pedidos feitos por eles. 
Rodrigo Marques, Aline Oliveira Vieira, Os sentidos Atribuídos pelos Jovens à Educação em Valores... Felipe Rodrigues Costa, Otávio Guimarães Tavares e

Wagner Santos

Contudo, não podemos deixar de destacar e considerar as complexidades envolvidas no processo de socialização dos jovens. Esses projetos são apenas uma experiência dentre vários espaços socializadores onde eles se inserem, portanto a incorporação de valores e comportamentos positivos nem sempre se dá da forma esperada (CASTRO; SOUZA, 2011).

\section{Sentidos da Função do "Eu” Estar em um Projeto Social}

Identificamos diferentes interesses influenciando a participação dos jovens no projeto social. Dentre eles, podemos apontar: a obrigação por parte da família; ser melhor que estar na rua; ter garantia de um estágio. No entanto, Charlot (2000) nos chama a atenção lembrando que, para que faça "um sentido para mim" "eu" devo ser um "sujeito de querer", isto é, participar de uma atividade de apropriação, de um saber que não possui.

O contexto familiar dos sujeitos atendidos pelo projeto social apresenta famílias desestruturadas, com carência. Esse cenário configura-se, segundo Gomes (2010), como umas das maiores fontes de exclusão social dos jovens em virtude dos casos graves de abandono parental, vivendo em condições degradantes habitacionais, com a agravante de residir em bairros marginalizados socialmente. Assim, para algumas famílias, o projeto se torna uma espécie de "depósito", contrariando parte dos jovens que não se interessam em frequentar esse lugar, como demonstram em suas narrativas:

$\mathrm{Eu}$ só venho aqui, para o projeto, para não ficar fazendo serviço em casa, [O que você aprende aqui, poderia aprender em outros lugares?]. $\mathrm{Na}$ escola sim (RICARDO, grupo Focal, 2014).

Mais ou menos, eu venho para o projeto social para não ficar na rua. $\mathrm{Eu}$ venho porque minha mãe me colocou, mas eu não gosto, não. [Se você não estivesse no projeto agora, o que estaria fazendo?] Soltando pipa ou jogando bola. [Você acha interessante ser obrigatório a 
Rodrigo Marques, Aline Oliveira Vieira, Os sentidos Atribuídos pelos Jovens à Educação em Valores... Felipe Rodrigues Costa, Otávio Guimarães Tavares e

Wagner Santos

frequentar as oficinas?) Eu acho que nós tínhamos que escolher (ROBERTO, grupo Focal, 2014).

A análise das entrevistas individualizadas com os seis jovens participantes nos evidenciou que três $(50 \%)$ participam do projeto porque são obrigados pela família. Quando perguntados sobre a obrigação de frequentar a oficina de valores, quatro (66,66\%) acham que não deveria ser obrigatória, pois não gostam de fazer dever, ler e também por ser enjoado ficar em sala; um $(16,66 \%)$ concorda que a oficina deve ser obrigatória, mas não gostaria de fazer todas as aulas; e um $(16,66 \%)$ concorda com a obrigatoriedade e gosta de participar da oficina.

Segundo Castro e Souza (2011), para as famílias, o projeto protege os jovens de uma possível socialização "negativa" das ruas, da violência, onde eles podem se envolver com "más influências," porém têm consciência de que a participação no projeto por si só não evita o envolvimento com problemas.

Quando a participação está atrelada à obrigação da família, percebemos que esses jovens se relacionam com os saberes de modo desinteressado. "Aprender faz sentido por referência à história do sujeito, às suas expectativas, às suas referências, à sua concepção de vida, às suas relações com os outros, à imagem que tem de si e a que quer dar de si aos outros" (CHARLOT, 2000, p. 72).

Os jovens são atores sociais, são protagonistas que trazem uma bagagem cultural e sentem necessidade de serem ouvidos. De acordo com Dayrell e Carrano (2014), eles nem são chamados para emitir opiniões e interferir nas questões que lhes dizem respeito diretamente, o que configura como um desestímulo à participação e ao protagonismo.

Por outro lado, os sentidos do "EU" frequentar o projeto apresentam benefícios quando os jovens enxergam nesse lugar as oportunidades que não teriam, por exemplo: nas ruas, expostos à violência, conforme evidenciam as narrativas: 
Rodrigo Marques, Aline Oliveira Vieira, Os sentidos Atribuídos pelos Jovens à Educação em Valores... Felipe Rodrigues Costa, Otávio Guimarães Tavares e

Wagner Santos

Se não fosse o projeto, eu estaria mexendo no celular. Sério mesmo, se eu não estivesse no projeto, estaria lá à toa, só à toa. [Então você acha que o projeto tem uma contribuição para sua vida?]. Não tem uma contribuição, não tem, é que ele me tira da rua, por exemplo: na rua eu posso estar sujeito a tudo, a uma bala perdida, ser atropelado... Como eles dizem: nós estamos de boa aqui, né? (RÔMULO, grupo Focal, 2014).

Os pontos positivos é que tira a gente da rua (ROBSON, grupo Focal, 2014).

Os jovens percebem que "a rua" é um local que oferece perigos, assim o projeto se configura como espaço praticável, cujo principal sentido é a proteção de possíveis riscos à sua integridade. Souza, Castro e Mezaddri (2012) entendem que um dos sentidos para os jovens participarem de projetos sociais é justamente o fato de eles serem percebidos como uma espécie de "porto seguro" que os protegem de supostos perigos das ruas.

Outra temática que se mostrou relevante para a participação dos jovens no projeto é a possibilidade de inclusão no mercado de trabalho por meio dos estágios. Mesmo que não se consiga trabalho para todos, eles o entendem como um elemento facilitador, já que o baixo poder aquisitivo dessas famílias estimula a inserção precoce nas atividades laborativas, como afirma Rômulo: “Arruma serviço para nós, pontos positivos eles tem estágio e arrumam para algumas pessoas" (RÔMULO, Grupo focal, 2014).

Não conseguimos evidências suficientes para dizer se o interesse pelos estágios proporcionados pelo projeto de fato parte dos jovens ou se eles sofrem influência de suas famílias, que visam, em seu trabalho, a uma melhoria de condição econômica, conforme evidenciam Feijó e Macedo (2012), quando afirmam que um dos principais interesses das famílias na participação dos jovens nos projetos é a busca pelo trabalho ou, no mínimo, a preparação para o mercado de trabalho. Já para Castro e Souza (2011), 
Rodrigo Marques, Aline Oliveira Vieira, Os sentidos Atribuídos pelos Jovens à Educação em Valores... Felipe Rodrigues Costa, Otávio Guimarães Tavares e

Wagner Santos

a possibilidade de o projeto conseguir trabalho para os jovens pode significar, para os seus familiares, a proteção das ruas ou prepará-los para o futuro.

Mas, em contrapartida, a obrigatoriedade de frequentar a oficina de valores humanos e as proximidades com as atividades escolares, como leitura e fazer dever, fazem do projeto um lugar que se assemelha à escola e que, na opinião dos jovens, não faz sentido, já que eles esperam que o projeto possa proporcionar-lhes novas experiências e oportunidades, ou seja, um espaço praticável.

Sobre a Oficina de Valores Humanos ser obrigatória e com atividades que se aproximam das realizadas na escola, sem que haja a oportunidade de os jovens serem ouvidos sobre seus desejos e anseios, legitimando sua condição de sujeito que se apropria e produz sentidos, eles relataram:

Não acho certo, pois, se a pessoa não quiser, não tem que fazer, não, mas tem que fazer outro. Não quer fazer Valores Humanos vai fazer Capoeira (ROSA, grupo Focal, 2014).

Eu não concordo, porque à tarde já passa dever na escola e chega no projeto e só sabe passar dever e depois explicar e eu já estou cansado (ROBERTO, grupo Focal, 2014).

Eu fui obrigado a fazer dever. Nós é que tínhamos que escolher as oficinas (REINALDO, grupo focal, 2014).

Para Charlot (2000), essa relação de obrigatoriedade torna os saberes produzidos pela Oficina de Valores Humanos de apropriação frágil, pois esse saber pouco apoio recebe da interação com os sujeitos que lhes dão um sentido específico, surtindo quase nenhum efeito na formação. De acordo com o autor, para que aconteça a produção de sentidos por determinados saberes, eles devem interessar àqueles que irão produzi-los.

Contudo, para outros jovens participantes do projeto, fica evidente que a apropriação dos saberes discutidos na Oficina de Valores Humanos fará mais sentido no 
Rodrigo Marques, Aline Oliveira Vieira, Os sentidos Atribuídos pelos Jovens à Educação em Valores... Felipe Rodrigues Costa, Otávio Guimarães Tavares e

Wagner Santos

futuro, quando forem adultos e assumirem suas obrigações sociais. Assim, projetam a educação em valores para o futuro, conforme suas narrativas:

Pode trazer muitas coisas boas, boa aprendizagem, ter um futuro melhor lá na frente (REBECA, entrevista individual, 2014).

Sentido tem tudo, mas é mais respeito e para o futuro ele vai fazer mais sentido para mim, porque agora eu estou começando a vida. Aprender essas coisas de respeito, respeitar outras pessoas, por exemplo, se eu tiver um filho, eu vou passar tudo que eu aprendi aqui, no projeto, para ele, para ele não ficar na rua, passar educação para ele (ROSANA, entrevista individual, 2014).

Lá na frente eu posso usar para eu viver melhor com as pessoas, para ajudar as pessoas que acham que tudo tem que ser na violência e que não tem que respeitar ninguém. Os valores vão fazer sentido na vida inteira. Praticando, eu levo junto comigo na convivência com a família e com os amigos, com novas pessoas e no trabalho para, quando meu chefe falar comigo, eu escutar (RÉGIS, Entrevista individual, 2014).

Ao projetar os sentidos que atribuem aos valores para o futuro, notamos uma tentativa de distanciamento com a atualidade, um desejo de transformação da atual realidade a que estão submetidos, como: respeito, educação, não violência, família, amigos, trabalho, valores que projetam o que deve ser o ideal para uma sociedade.

Para Santiago (1999), os mecanismos geradores das diferenças que acometem o presente desses jovens fortalecem a avaliação feita por eles da apropriação e produção de sentidos, de suas experiências passadas, em relação às atuais, e ainda encontram algumas possibilidades de projeção da utilização desses valores para projetos futuros.

Para que os jovens alcancem seus objetivos projetados para o futuro, o engajamento participativo contribui, segundo Dayrell e Carrano (2014), aumentando o estímulo para novas aprendizagens, provocando o desenvolvimento da capacidade de argumentação para defesa do seu ponto de vista. Nesse sentido, a participação no projeto pode ser entendida como um processo educativo que potencializa os processos de aprendizagem. 
Rodrigo Marques, Aline Oliveira Vieira, Os sentidos Atribuídos pelos Jovens à Educação em Valores... Felipe Rodrigues Costa, Otávio Guimarães Tavares e

Wagner Santos

\section{Sentidos com a Educação Enunciada em Valores}

A Oficina de Valores Humanos do projeto social, junto com as demais oficinas, foi criada com o objetivo de dar visibilidade ao que a Cartilha de Valores Humanos considera como os grandes valores que formam as pessoas como cidadãos: família, identidade, meio ambiente, afetividade/sexualidade, cidadania etc. O planejamento do professor aborda a temática eleita na reunião mensal a partir de aulas expositivas, vídeos, textos, construção de cartazes etc.

Os jovens narradores, ao serem indagados sobre o praticado na Oficina de Valores, relatam suas tensões e estranhamento com a ação pedagógica construída. Eles enfatizam a desmotivação com a forma como as práticas são conduzidas pelo professor, que se configuram como uma abordagem dos valores de modo conceitual. Ao enunciar os conceitos de valores, o educador social assume uma metodologia que afasta o sujeito do processo de ensino, tornando-o passivo, o que lhes causa desinteresse e falta de participação voluntária, conforme sinalizam as narrativas:

Parece a escola. É chato. Eles mandam a gente fazer dever, caçar palavras, escrever e fazer cartaz (RICARDO, grupo focal, 2014).

Eles passam filme e depois mandam a gente fazer dever e eu não gosto de fazer dever (RICARDO, grupo focal, 2014).

Enche o quadro, passa, apaga, passa, apaga. Para os pequenos, ela dá dever para pintar, passa caça-palavras e nós, que somos grandes, temos que copiar textos (REBECA, grupo focal, 2014).

A passividade em relação aos saberes não lhes permite apropriar-se de uma forma intersubjetiva, ou seja, que garanta um controle do seu desenvolvimento pessoal, ou o que Charlot (2000) conceituou como distanciação-regulação, em que o sujeito é entendido como epistêmico, afetivo e relacional, definido por sentimentos e emoções em situação e em ato, nas relações com os outros e consigo mesmo. 
Rodrigo Marques, Aline Oliveira Vieira, Os sentidos Atribuídos pelos Jovens à Educação em Valores... Felipe Rodrigues Costa, Otávio Guimarães Tavares e

Wagner Santos

Bonotto (2008) considera ser importante a realização de um trabalho educativo que reconheça que a abordagem dos valores não pode estar restrita ao cognitivo, pois os desafios apresentados cotidianamente resultam em uma constante tensão para a otimização da vida pessoal. Nessa direção, Menin (2002) aponta que os valores devem ser vivenciados, ou seja, não se ensina cooperação como um valor sem praticá-la; não se ensina justiça, sem a reflexão sobre os modos equilibrados de se resolver conflitos; e não se ensina tolerância sem a prática do diálogo.

A educação em valores demanda ações socialmente complexas que atravessam questões relacionadas com a família, a escola, a religião e outras esferas que contemplem a formação dos sujeitos baseadas nas questões morais e éticas. Para Ponce (2009), a educação do sujeito moral deve ser fundada na liberdade de pensamento e na responsabilidade, não se tratando apenas de ditar as regras e fazer cumpri-las.

No projeto social, a Oficina de Valores Humanos aborda seus conteúdos de maneira conceitual que, para Barroso e Darido (2009), se refere ao "que se deve saber". Nesse sentido, é priorizado na oficina que os alunos aprendam sobre o que são, quais são os valores e sua importância para a formação dos jovens. A abordagem conceitual dos valores apresenta um caráter de ensino de modo exortativo que, para Knijnik e Tavares (2012), está relacionado com o ensino das condutas, comportamentos e um modo de agir favorável, sem, no entanto, desenvolver situações práticas.

Knijnik e Tavares (2012) identificaram nos textos orientadores de um projeto social, e nas falas dos professores diretamente envolvidos nas atividades cotidianas, três abordagens didáticas para o ensino da dimensão atitudinal da educação. São elas:

Abordagem incidental: caracteriza-se por uma ação reativa. Ou seja, a ação didática se dá após a ocorrência de uma situação considerada como problemática. 
Rodrigo Marques, Aline Oliveira Vieira, Os sentidos Atribuídos pelos Jovens à Educação em Valores... Felipe Rodrigues Costa, Otávio Guimarães Tavares e

Wagner Santos

Porém, o conteúdo da dimensão atitudinal (os valores) pode ou não estar previsto no planejamento de ensino do docente. Assim, o ensino objetivado em valores ocorre apenas se e quando houver uma situação que o requeira.

Abordagem exortativa: geralmente associada à abordagem incidental, caracteriza-se pelo ensino de valores por meio do discurso. Geralmente é utilizado para condenar, confirmar ou estimular um determinado comportamento ou atitude por meio da fala, não implicando necessariamente em reflexão, exposição a um dilema e debate com os educandos.

Abordagem intrínseca: Caracteriza-se pelo ensino em valores por meio de alguma prática que se considere intrinsecamente educativa. Assim, o ensino em valores se dá por meio da experimentação e vivência de alguma prática que se entende naturalmente portadora de valores e que neste contexto serão assimilados pelos praticantes.

Não afirmamos que essas abordagens estejam erradas ou que sejam ineficientes, porém, em confronto com a teoria construtivista, estas não parecem ser as mais completas ou eficientes. Todavia, deve-se reconhecer as dificuldades existentes em construir evidências empíricas da relação causal de qualquer abordagem ou estratégia da educação em valores.

Assim, ao igualar sua metodologia com os espaços e tempos escolares, a Oficina de Valores Humanos deixa de ser para os jovens o diferencial em meio às demais esferas sociais que abordam a educação em valores: família, escola, igreja etc. Segundo os jovens, a educação em valores faz pouca ou nenhuma diferença na sua formação, conforme narrativas:

Para mim, faz pouca diferença, porque as parada que os outros falam da licença, só quando é preciso mesmo, porque a maioria aqui fala 'Ae 
Rodrigo Marques, Aline Oliveira Vieira, Os sentidos Atribuídos pelos Jovens à Educação em Valores... Felipe Rodrigues Costa, Otávio Guimarães Tavares e

Wagner Santos

veado, é nós', 'Fala e ae', e às vezes falamos normal (RÔMULO, grupo focal, 2014).

Eu não acho a Oficina de Valores Humanos importante, porque ela passa muito dever e isso vai contribuir mais ou menos para minha vida (RICARDO, grupo focal, 2014).

Aqui, neste projeto, para mim mesmo, é só perda de tempo, porque eu só venho aqui para não ficar em casa fazendo nada (RÔMULO, entrevista individual, 2014).

Entendemos que os jovens não são consumidores passivos (CERTEAU, 2012); eles se apropriam daquilo que para eles faz sentido, que promove experiências significativas e que contribua para seu processo formativo. Eles são produtores de opiniões, fazem relações com o ofertado, mas necessitam de um aprendizado de acordo com a demanda de sua idade, de expectativas ou, conforme Dayrell e Carrano (2014), os jovens constituem culturas que os identificam como jovens. Com expressões simbólicas, ganham destaque por meio dos mais diferentes estilos, pois eles querem ser reconhecidos, querem visibilidade, enfim, querem ser alguém em contextos em que comumente são invisíveis.

Assim, a Oficina de Valores Humanos deve buscar desenvolver atividades atrativas e desafiadores e considerar os jovens como sujeitos capazes de entender os acontecimentos que os cercam, que ocupam seu lugar na sociedade, que assumem suas responsabilidades e saibam lidar com suas experiências. Então, autonomia deve ser a base da construção e da intervenção em valores fundamentais à sua formação.

Por outro lado, percebemos que, nos momentos em que a didática da Oficina de Valores Humanos aborda a temática de valores por meio de filmes ${ }^{11}$ e jogos, ${ }^{12}$ o que Charlot (2000) chamou de objeto-saberes, isto é, objetos aos quais um saber está

\footnotetext{
${ }^{11}$ Filme Matilda, que retrata a história de uma garotinha que vive em uma família conturbada, em que o pai é um vendedor de carros desonesto que tenta ensinar para os filhos essa forma de ganhar dinheiro fácil.

${ }^{12}$ Jogo do tabuleiro humano na sala estimulou a participação e interação entre os alunos que formavam equipes para responder às questões referentes aos valores humanos.
} 
Rodrigo Marques, Aline Oliveira Vieira, Os sentidos Atribuídos pelos Jovens à Educação em Valores... Felipe Rodrigues Costa, Otávio Guimarães Tavares e

Wagner Santos

incorporado - livros, monumentos, obras de arte, programas de televisão - os jovens evidenciam maior interesse, identificação e sentido de pertencimento, conforme captado nas anotações do diário de campo:

Os jovens, ao identificarem que o pai de Matilda é um trapaceiro, quando diz que sua televisão é roubada, eles resmungam em suas carteiras: 'Pilantra', 'Vagabundo', 'Ladrão'. Eles também reconhecem o modo autoritário da diretora da escola onde Matilda estuda. Quando ela grita com os alunos para que eles calem a boca, eles retrucam: 'Vasa sua louca', 'Cala a boca você', mostrando uma empatia com a garotinha que é totalmente o oposto de sua família, é educada, estudiosa e sonhadora (Anotação no diário de campo, 2014).

Durante uma aula em que foi realizada um jogo chamado jogo da velha humano, onde os jovens representavam o $\mathrm{X}$ e $\mathrm{O}$, eles foram divididos em dois grupos e tinham um líder que ouvia a sugestão de todos os membros da equipe, porém ele era o responsável por decidir a jogada. Houve dedicação, interesse pela atividade. Foram trabalhados os valores destacados pelos alunos: responsabilidade, paciência, comunicação, flexibilidade, clareza (Anotação no diário de campo, 2014).

Há, nessas práticas, um conhecimento de si. Os jovens relacionam-se e apropriam-se dele, são os proprietários do seu próprio saber-fazer, o que lhes permite o poder de articular.

$\mathrm{Na}$ formação da identidade juvenil, o jogo proporciona uma desrealização do real, mas também a concretização de novas vivências da realidade. Assim, para Pais (2006, p.12):

O mundo real, da 'vida verdadeira' é cheio de incertezas. Em contrapartida, nos jogos de computador e vídeo, exercitam um poder performativo: ao utilizarem um simulador de voo, sentem-se pilotos; como jogadores, interiorizam a missão de herói. Para os próprios hackers, o desafio é expressarem sua capacidade de domínio sobre o computador edificando uma cultura de façanhas, desafios, descobertas, sem esquecer a possibilidade de derrubarem os sistemas de segurança das redes de informática.

Entendemos que as práticas didático-pedagógicas, como jogos, brincadeiras lúdicas, vídeos, são qualitativos, modos de apropriação e produção de sentidos que formam novas experiências que, para Pagni (2010), são valorizadas como um modo de 
Rodrigo Marques, Aline Oliveira Vieira, Os sentidos Atribuídos pelos Jovens à Educação em Valores... Felipe Rodrigues Costa, Otávio Guimarães Tavares e

Wagner Santos

conhecer o mundo e a si, ao acompanhar o desenvolvimento subjetivo do homem, com sensibilidade e razão nos julgamentos empreendidos sobre os resultados e utilidades dos saberes por eles produzidos.

\section{Sentidos com as Práticas Corporais: O Fazer com as Oficinas}

Ao observarmos as práticas da docente da Oficina de Educação Física, identificamos que a professora constrói suas aulas mediante uma tensão entre o prescrito $^{13}$ e o praticado. ${ }^{14}$ A especificidade de sua oficina fica, muitas vezes, atrelada à forma conceitual e exortativa como o projeto entende que devam ser os saberes da educação em valores, conforme nos foi narrado:

Existe uma reunião de planejamento entre a direção e os educadores uma vez por mês, e aí é falado qual o tema será trabalhado para todo mundo. Aí se conversa sobre o assunto [...] é falado como vamos trabalhar e como vamos conversar. Também quando acontece alguma coisa que não está sendo bem trabalhado, a direção nos fala (EDUCADORA Social da Oficina de Educação Física, entrevista individual, 2014).

Esses valores já vêm das diretrizes. O segundo semestre foi acordado com os pais, no ano passado. Foi levantado pela própria equipe, então não tem meio que uma autonomia, é um acordo de grupo mesmo. $\mathrm{Na}$ reunião que temos, mensal, a gente consegue estipular o que vai ser trabalhado (EDUCADOR Social da Oficina de Valores Humanos, entrevista individual, 2014).

Ao analisarmos o Projeto Político-Pedagógico, percebemos que a Oficina de Educação Física, assim como as demais oficinas do projeto, é um meio para alcançar o objetivo de educar em valores. Há indícios de que seja utilizada como uma forma de atrair os jovens para participar das atividades propostas. Todavia, quando se observa o

\footnotetext{
${ }^{13} \mathrm{O}$ conteúdo prescrito parte da reunião mensal feita entre a coordenação do projeto e os educadores sociais, para decidirem a temática sobre os valores a serem trabalhados por um período determinado, partindo da Cartilha de Valores Humanos ou conforme necessidades identificadas na participação dos jovens.

${ }^{14}$ Planejamento das aulas de responsabilidade da professora responsável pela Oficina de Educação Física.
} 
Rodrigo Marques, Aline Oliveira Vieira, Os sentidos Atribuídos pelos Jovens à Educação em Valores... Felipe Rodrigues Costa, Otávio Guimarães Tavares e

Wagner Santos

praticado na Oficina de Educação Física, os jovens narram com estranhamento e desinteresse as atividades ali desenvolvidas, não as vendo como atrativas.

A Oficina de Educação Física indicia representar, pela visão do jovem, o não lugar do aluno, já que ele não opina sobre os conteúdos e é obrigado a participar de atividades que não são atrativas, sob pena de ser enviado à coordenação, configurandose estratégias que não lhe oportunizam condições de autonomia, conforme relato dos jovens:

Educação física a gente já faz na rua, que é só jogar bola; aqui nos só ficamos correndo de um lado para o outro (RÔMULO, entrevista individual, 2014).

A professora só passa atividade besta e nós quase se mata se machucando. Deveria deixar a gente mais livre para nós jogarmos bola, vôlei e outras melhores (ROBERTO, entrevista individual, 2014).

Ela passa brincadeiras que não sabemos e quer que nós façamos e, se não fizermos, ela manda conversar com o coordenador (RICARDO, grupo focal, 2014).

Essa tensão se manifesta na sua relação com os jovens que esperam que a educação física seja diferente da Oficina de Valores Humanos e do que é praticado na rua. O olhar que os jovens lançam sobre as atividades da Oficina de Educação Física é o do momento da prática, que se diferencia do que é vivenciado na rua ou, ainda, que considere seus interesses. No não atendimento a essas sinalizações, aparecem as divergências, o desinteresse e a dispersão, motivos suficientes para favorecer os conflitos, as intrigas, exatamente os contravalores, diagnóstico que justifica a intervenção em valores nas práticas corporais.

Esses fatos nos faz compreender, concordando com Dayrell e Carrano (2014), que os jovens são capazes de refletir e de se ver como indivíduo que participa da sociedade, que recebe e exerce influências, sobretudo nessa fase da vida, por excelência, 
Rodrigo Marques, Aline Oliveira Vieira, Os sentidos Atribuídos pelos Jovens à Educação em Valores... Felipe Rodrigues Costa, Otávio Guimarães Tavares e

Wagner Santos

do exercício de inserção social, fazendo parte dos tempos, espaços e relações de qualidade que possibilitem a experimentação de novas experiências.

Para que ocorra o processo de apropriações das práticas, é necessário, segundo Santos et al. (2014), provocar novas leituras em um movimento de ação-reflexão-ação, ampliando o conhecimento que os jovens possuem sobre os valores, compreendendo o seu lugar no próprio processo de formação.

\section{Quando o Valor faz Sentido: A Educação em Valores no Fazer com a Capoeira,}

\section{Break Dance e Xadrez}

Para que aconteça uma apropriação dos valores, existe necessidade de que esses jovens estejam interessados, disponíveis para esses aprendizados, pois, de acordo com Charlot (2000), só existe o aprendizado quando o indivíduo se propõe a aprender, quando se relaciona com o objeto.

Posto isso, entendemos que a produção de sentidos começa quando nos mobilizamos, quando podemos escolher o que fazer (aspecto motivador). Para Charlot (2000), existe a mobilização quando se investe em uma atividade, quando se faz uso de si mesmo como um recurso que remete a um desejo, um sentido, um valor.

O xadrez ajuda no pensamento, como vai ser a jogada, o raciocínio e ter ideia para jogar (RENZO, grupo focal, 2014).

A capoeira tem seus valores. Ensina a gente a lutar, se defender e não ficar usando para brigar, não. Ela ensina o que eu não sei se é uma dança ou uma luta. Não pode usar na rua para querer machucar os outros; capoeira é só para ver a beleza (RÔMULO, grupo focal, 2014).

A capoeira antigamente era muito agressiva, machucava e hoje é uma oficina boa, que desenvolve os movimentos e a ginga (RÔMMUO, grupo focal, 2014).

Eu faria algumas aulas de educação em valores. Quando tivesse chata, eu não gostaria de fazer, ou eu prefiro não vir. Nas oficinas que eu gosto eu venho numa boa, mas eu gosto mesmo é de jogar a capoeira, jogar o xadrez (REGIS, entrevista Individual, 2014). 
Rodrigo Marques, Aline Oliveira Vieira, Os sentidos Atribuídos pelos Jovens à Educação em Valores... Felipe Rodrigues Costa, Otávio Guimarães Tavares e

Wagner Santos

Eu gostaria de aprender dançar breik dance, mais só que eu sou muito dura, aí não dá. Eu também eu quero terminar de aprender capoeira, eu achei muito legal (ROSANA, grupo focal, 2014).

As narrativas nos apresentam a necessidade de desvendar as atividades performativas dos jovens ao invés de aprisioná-los em modelos prescritivos com os quais eles não se identificam. Nesse caso, o break dance e o xadrez são práticas com que os jovens se identificam, pois trazem, no modo como são trabalhadas, o protagonismo juvenil, aproximando os jovens dos amigos, proporcionando diversão.

A apropriação e produção de sentidos que os jovens atribuem ao fazer com a capoeira, break dance e xadrez, apresenta relações com a tradição da técnica e da prática corporal, influenciadas pelo saber domínio, que consiste em dominar uma atividade ou capacitar-se a utilizar um objeto de forma pertinente, passar do não domínio ao domínio de uma atividade (CHARLOT, 2000).

Essas oficinas configuram-se como técnicas corporais determinadas pela cultura, e a modernidade tende a valorizá-las. São construções culturais que surgiram em contextos históricos e socialmente concretos. São uma tradição que os mais velhos divulgam, incorporando novas transformações que se referem a novos significados atribuídos aos hábitos culturais de cada grupo.

Poder escolher frequentar umas dessas oficinas confere ao jovem autonomia para atribuir sentidos à pratica da modalidade. É o que o mobiliza a relacionar-se com o objeto, expondo as divergências entre o que é proposto no prescrito pelo projeto e a obrigatoriedade de aceitar o fato de que os seres humanos são diferentes, cobrando a participação na Oficina de Valores Humanos.

De acordo com Lira e Dimenstein (2004), os programas voltados para os jovens devem trabalhar em parceria com eles, estimulando seu papel de protagonistas no planejamento, na implementação e na avaliação das atividades propostas. 
Rodrigo Marques, Aline Oliveira Vieira, Os sentidos Atribuídos pelos Jovens à Educação em Valores... Felipe Rodrigues Costa, Otávio Guimarães Tavares e

Wagner Santos

Quando a atividade é importante para eles, faz sentido, entra em um dispositivo relacional com o mundo, como um conjunto de situações e relações nas quais eles estão engajados como um sujeito encarnado, ativo, temporal, provido de afetividade. Sua relação com um mundo (CHARLOT, 2000) difere da Oficina de Valores Humanos, enquanto o fazer com o xadrez e a capoeira estabelece uma identificação com o jovem, algo que não é uma novidade, mas que difere das práticas corporais na escola, na rua etc.

\section{Considerações Finais}

O estudo revelou que a principal proposta de intervenção da educação em valores dentro do projeto social se dá por intermédio da Oficina de Valores Humanos, em que são priorizados os saberes prescritos na Cartilha de Valores Humanos. Seu principal modo de mediação pedagógica acontece de forma exortativa, usando estrategicamente a obrigatoriedade de frequentar a oficina como um dos requisitos para fazer parte do projeto e das oficinas de práticas corporais.

Dentro dos projetos sociais, a educação física pode, por meio das práticas corporais, contribuir para a mediação de conhecimentos, valores, significados e normas sociais que estimulem os jovens a apropriar-se de uma visão mais crítica da realidade em que estão inseridos, exercitando sua capacidade de atribuir sentidos, desenvolver ações cooperativas e estruturá-las, benefícios significativos que podem produzir mudanças no seu convívio familiar, escolar e até mesmo nas ruas.

A Oficina de Valores Humanos é a principal referência de mediação de valores no projeto social para esses jovens, contudo, ao priorizar o modo exortativo, o educador torna sua intervenção pouco atrativa para eles. Entendemos que os jovens demandam 
Rodrigo Marques, Aline Oliveira Vieira, Os sentidos Atribuídos pelos Jovens à Educação em Valores... Felipe Rodrigues Costa, Otávio Guimarães Tavares e

Wagner Santos

interesse especial pelas atividades práticas, atribuindo sentidos à sua participação no fazer com, ao se reconhecerem como protagonistas.

As práticas corporais a serem dominadas oferecem aos jovens a motivação necessária para encarar as adversidades, e a liquidez de seu mundo em constantes mudanças torna dinâmico o processo de apropriação e produção de sentidos, trazendo desafios que aproximam a sua realidade do projeto, ou seja, oferece sentido de pertencimento ao lugar.

Esse protagonismo juvenil torna-os elemento central da prática educativa, participantes de toda a fase de construção e elaboração das estratégias de intervenção. Ocupando uma posição, eles passam a exercitar a cidadania expondo a mensagem de como é o seu mundo real, por sua ótica, ressaltando a diversidade e vivenciando aquilo que por experiência faz sentido, que se experimenta, não fica no faz de conta.

Como exemplo, temos a tensão instaurada nas práticas (Oficina de Valores e de Educação Física) que se aproximam de uma ação escolarizada e que não utilizam o movimento como meio de linguagem, revelando-nos que existe a necessidade de repensar as práticas pedagógicas que são desenvolvidas dentro dos projetos sociais, levando em consideração que é preciso construir um corpo de conhecimentos no campo teórico-metodológico que pense a partir do interesse dos jovens e da lógica do projeto e não da escola.

O fato de "dar voz" aos jovens, principalmente na construção dos planejamentos, para exporem suas necessidades, desejos e anseios, evidenciará pistas para que, no processo de intervenção, as atividades façam sentido para eles e os coloquem em condição de praticantes desse lugar, reconhecidos pelo seu protagonismo. 
Rodrigo Marques, Aline Oliveira Vieira, Os sentidos Atribuídos pelos Jovens à Educação em Valores... Felipe Rodrigues Costa, Otávio Guimarães Tavares e

Wagner Santos

Assim, fazem-se necessárias novas pesquisas que dialoguem com a juventude participante de projetos sociais, escolas e instituições que promovam o processo de ensino socioeducativo, para identificar como e se acontece na prática o protagonismo e a produção de sentidos dessas culturas juvenis.

\section{REFERÊNCIAS}

ABRAMOVAY, Miriam; ANDRADE, Eliane Ribeiro; ESTEVES, Luiz Carlos Gil. Juventudes: outros olhares sobre a diversidade. 2007. Disponível em: < http://unesdoc.unesco.org/images/0015/001545/154580POR.pdf> . Acesso em: 22 abr. 2014.

BARROSO, André Luís Ruggiero; DARIDO, Suraya Cristina. A pedagogia do esporte e as dimensões dos conteúdos: conceitual, procedimental e atitudinal. Revista da Educação Física/UEM, Maringá, v. 20, n. 2, p. 281-289, 2. trim. 2009. Disponível em: $<$ http://www.periodicos.uem.br/ojs/index.php/RevEducFis/article/view/3884/4440>.

Acesso em 22 set. 2014.

BELO HORIZONTE. Prefeitura Municipal. Secretaria Municipal Adjunta de Assistência Social. Dicionário de termos técnicos da assistência social. Belo Horizonte: ASCOM, 2007. Disponível em: http://pt.slideshare.net/alavieira/dicionariotermos-tecnicos-da-assistencia-social . Acesso em: $21 \mathrm{dez} .2015$.

BENJAMIN, Walter. Magia e técnica, arte e política ensaios sobre literatura e história da cultura. Obras escolhidas. 3. ed. São Paulo: Editora Brasiliense, 1987.

BONOTTO, Dalva Maria Bianchini. Educação ambiental e educação em valores em um programa de formação docente. 2008. Disponível em: http://reec.uvigo.es/volumenes/volumen7/ART3_Vol7_N2.pdf . Acesso em: $22 \mathrm{dez}$. 2014.

CASTRO, Suélen Eiras de; SOUZA, Doralice Lange. Significados de um projeto social esportivo: um estudo a partir das perspectivas de profissionais, pais, crianças e adolescentes. Movimento, Porto Alegre, v. 17, n. 4, p. 145-163, out./dez. 2011.

CERTEAU, M. A invenção do cotidiano: [1.] artes de fazer. 12. ed. Petrópolis: Vozes, 2012.

CHARLOT, Bernard. Da relação com o saber: elementos para uma teoria. Porto Alegre: Artimed, 2000.

2001.

Os jovens e o saber: perspectivas mundiais. Porto Alegre: Artmed Editora, 
Rodrigo Marques, Aline Oliveira Vieira, Os sentidos Atribuídos pelos Jovens à Educação em Valores... Felipe Rodrigues Costa, Otávio Guimarães Tavares e

Wagner Santos

DAYRELL, Juarez; CARRANO, Paulo. Juventude e ensino médio: quem é este aluno que chega a escola. In: DAYRELL, Juarez; CARRANO, Paulo; MAIA, Carla Linhares (Org.). Juventude e ensino médio: sujeitos e currículo em diálogo. Belo Horizonte: Editora UFMG, 2014.

DIAS, Cláudia Augusto. Grupo focal: técnica de coleta de dados em pesquisas qualitativas. $2000 . \quad$ Disponível em: <bogio.eci.ufmg.br/downloads/dias\%20grupofocal.pdf> . Acesso em: 25 nov. 2014.

FEIJÓ, Marianne Ramos; MACEDO, Rosa Maria Stefanini de. Família e projetos sociais voltados para jovens: impacto e participação. Estudos de Psicologia, Campinas, v. 29, n. 2, p. 193-202, abr.jun. 2012.

FREITAS, Giovane Jacó de. Juventude e ensino médio: perspectivas da sociologia entre conquistas e desafios. In: GONÇALVES, Nilin Danyelle (Org.). Sociologia e juventude no ensino médio: formação PIBID e outras experiências. Campinas. Pontes Editora, 2013. p. 101-112.

GARANHANI, Marynelma Camargo; TASSA, Khaled Omar Mohamad El. Formação profissional para atuação em projetos sociais: no foco a formação de professores no"programa Segundo Tempo". Movimento, Porto Alegre, v. 19, n. 4, p. 273-287, out./dez. de 2013.

GOMES, Ana Cristina Ramos. Educar para os valores. 2010. Disponível em: http://repositorio.ul.pt/handle/10451/4114 . Acesso em: 27 jul. 2013.

KNIJNIK, Jorge Dorfman; TAVARES, Otávio Guimarães. Educating Copacabana: a critical analysis of the Second Half, an Olympic Education Program of Rio, 2016. Educational Review (Birmingham), v. 64, p. 353-368, 2012.

LEMOS, Kátia Lúcia Moreira. Educação física e valores: análise centrada em discursos de professores e alunos de escolas do ensino fundamental médio da cidade de Belo Horizonte. 2006. <Disponível em: http://hdl.handle.net/10216/22983> . Acesso em: 25 fev. 2013.

LIRA, Joseneide Barbosa de; DIMENSTEIN, Magda. Adolescentes avaliando um projeto social em uma unidade básica de saúde. Psicologia em Estudo, Maringá, v. 9, n. 1, p. 37-45, 2004.

LUCAS, Maria Paula; PEREIRA, Beatriz; MONTEIRO, Alberto de Oliveira. Desporto escolar uma construção a partir dos valores. Braga: Centro de investigação em estudos da criança - Instituto de Educação - Universidade do Minho, 2012, p. 153-165.

MAZO, Jones Zarpellon. Os valores do esporte juvenil: um estudo com jovens participantes em projetos pró-sociais no município de Santo Ângelo, Rio Grande do Sul. 2011. Disponível em: https://www.lume.ufrgs.br/bitstream/handle/10183/.../000788383.pdf? . Acesso em: 22 set. 2014. 
Rodrigo Marques, Aline Oliveira Vieira, Os sentidos Atribuídos pelos Jovens à Educação em Valores... Felipe Rodrigues Costa, Otávio Guimarães Tavares e

Wagner Santos

MELLO et al. Educação física e esporte: reflexões e ações contemporaneas. Movimento, v. 17, n. 2, 2009, p. 175-193.

MENIN, Maria Susana De Stefano. Valores na escola. Educação e Pesquisa, São Paulo, v.28, n.1, p. 91-100, jan./jun. 2002.

MOLINA, Rosane Kreusburg; SILVA, Lisandra Oliveira; SILVEIRA, Fabiano Vaz da. Celebração e transgressão: a representação do esporte na adolescência. Rev. bras. Educ. Fís. Esp., São Paulo, v.18, n. 2, p. 125-36, abr./jun. 2004.

PAGNI, Pedro. Um lugar para a experiência e suas linguagens entre os saberes e práticas escolares: pensar a infância e o acontecimento na práxis educativa. In: PAGNI, A. P. GELAMO, R. P. (Org.). Experiência e educação e contemporaneidade. Editora Cultura Acadêmica, Marília/SP, 2010. p. 13-33.

PAIS, José Machado. Culturas juvenis. Lisboa: Imprensa Nacional-Casa da Moeda, 1993.

Buscas de si: expressividades e identidades juvenis. In: ALMEIDA, Maria Isabel Mendes de; EUGENIO, Fernanda (Org.). Culturas jovens novos mapas do afeto. Rio de Janeiro: Jorge Zahar Editora, 2006.

PIAGET, Jean. Seis estudos de psicologia. Tradução de Maria Alice Magalhães D'Amorim e Paulo Sergio Lima Silva. 24. ed. Rio de Janeiro: Forense Universitária, 2003.

PONCE, Branca Jurema. A educação em valores no currículo escolar. 2009. Disponível em: http://www.pucsp.br/curriculum . Acesso em: 03 jul. 2013.

PRADEL, Cláudia; DAÚ, Jorge Alberto Torreão. A educação para os valores e as políticas 2009. Disponível em: http://www.scielo.br/pdf/ensaio/v17n64/v17n64a07.pdf . Acesso em: 26 mar.2013.

RAPPAPORT, Clara Regina. Teorias do desenvolvimento: conceitos fundamentais. 1981. Disponível em: http://psicoeducauff.files.wordpress.com/2012/03/piaget.pdf . Acesso em: 12 out. 2014.

SPOSITO, Marília Pontes. Estado da arte sobre a juventude na pós-graduação brasileira: educação, ciências sociais e serviço social (1999-2006). v.2. Belo Horizonte, MG: Argumentum, 2009.

SALDANHA, Ricardo Pedrozo. Valores e atitudes de jovens praticantes de esportes em projetos sociais: um modelo teórico-explicativo. 2012. Tese (Doutorado em Educação Física) - Universidade Federal do Rio Grande do Sul, Escola de Educação Física, Programa de Pós-Graduação em Ciências do Movimento Humano, Porto Alegre, 2012 .

SANTIAGO, Leonéa Vitória. Os valores orientadores das práticas desportivas em grupos emergentes da terceira idade: um estudo sobre as construções simbólicas. 
Rodrigo Marques, Aline Oliveira Vieira, Os sentidos Atribuídos pelos Jovens à Educação em Valores... Felipe Rodrigues Costa, Otávio Guimarães Tavares e

Wagner Santos

1999. <Disponível em: http://repositorio-aberto.up.pt/handle/10216/10009> . Acesso em: 25 nov. 2014.

SANTOS, Verônica Freitas dos et al. Educação física e o processo de escolarização: uma análise sob a perspectiva do aluno. Revista da Educação Física/UEM, Maringá, v. 25, n. 4, p. 539-553, 4. trim. 2014. Disponível em: < http://www.scielo.br/pdf/refuem/v25n4/1983-3083-refuem-25-04-00539.pdf $>$. Acesso em: 23 de nov. 2014.

SARMENTO, Manuel Jacinto. O estudo de caso etnográfico em educação. In: ZAGO, Nadir; CARVALHO, Marília Pinto de; VILELA, Rita Amélia Teixeira (Org.). Itinerários de pesquisa: perspectivas qualitativas em sociologia da educação. Rio de Janeiro: DP\&A, 2003. p. 137-179.

SAWITZKI, Rosalvo Luís et al. Retomada de valores e mudanças atitudinais: uma experiência no programa social cidadão UFSM/CEFD. Licere, Belo Horizonte, v. 16, n. 3, set. 2013.

SOUZA, Doralice Large de; CASTRO, Suélen Barbosa Eiras de; MEZZADRI, Fernando Marinho. Facilitadores e barreiras para a implementação e participação em projetos sociais que envolvem atividades esportivas: os casos dos projetos Vila na Escola e Esporte Ativo. Rev. Bras. Educ. Fís. Esporte, São Paulo, v. 26, n. 3, p. 41930, jul./set. 2012.

WERNECK, Vera Rudge. Novos valores ou nova hierarquia de valores? Meta: Avaliação. Rio de Janeiro, v. 2, n. 4, p. 73-86, jan./abr. 2010.

\section{Endereço dos Autores:}

Rodrigo Marques

Rua 8, 228, Cocal

Vila Velha - ES - 29.105-780

Endereço Eletrônico: rodrigo30mar_@hotmail.com

Aline Oliveira Vieira

Wilson Duarte Silva, 27, Manguinhos

Serra - ES - 29.173-078

Endereço Eletrônico: ninna.maguinhos@gmail.com

Felipe Rodrigues Costa

SQN, 109, Bloco J, apto 603, Asa Norte

Brasília - DF - 70.752-100

Endereço Eletrônico: fcostavix@gmail.com

Otávio Guimarães Tavares

Av. Fernando Ferrari, 514, Goiabeiras

Vitória - ES - 29.075-910 
Rodrigo Marques, Aline Oliveira Vieira, Os sentidos Atribuídos pelos Jovens à Educação em Valores... Felipe Rodrigues Costa, Otávio Guimarães Tavares e

Wagner Santos

Endereço Eletrônico: tavaresotavio@yahoo.com.br

Wagner dos Santos

Carlos Eduardo Monteiro de Lemos, 261, apto 104, Jardim da Penha

Vitória - ES - 29.680-120

Endereço Eletrônico: wagnercefd@gmail.com 